\title{
Low transformation growth factor- $\beta 1$ production and collagen synthesis correlate with the lack of hepatic periportal fibrosis development in undernourished mice infected with Schistosoma mansoni
}

\author{
Andreia Ferreira Barros ${ }^{1}$, Sheilla Andrade Oliveira ${ }^{1 /+}$, Camila Lima Carvalho ${ }^{1}$, \\ Fabiana Leticia Silva², Veruska Cintia Alexandrino de Souza ${ }^{1}$, Anekecia Lauro da Silva', \\ Roni Evencio de Araujo', Bruno Solano F Souza ${ }^{3,4}$, Milena Botelho Pereira Soares ${ }^{3,4}$, \\ Vlaudia MA Costa ${ }^{2}$, Eridan de Medeiros Coutinho ${ }^{1}$
}

\footnotetext{
${ }^{1}$ Laboratório de Imunologia e Biologia Molecular, Centro de Pesquisa Aggeu Magalhães-Fiocruz, Recife, PE, Brasil ${ }^{2}$ Departamento de Medicina Tropical, Centro de Ciências da Saúde, Universidade Federal de Pernambuco, Recife, PE, Brasil ${ }^{3}$ Laboratório de Engenharia Tecidual e Imunofarmacologia, Centro de Pesquisa Gonçalo Moniz-Fiocruz, Salvador, BA, Brasil ${ }^{4}$ Centro de Biotecnologia e Terapia Celular, Hospital São Rafael, Salvador, BA, Brasil
}

\begin{abstract}
Undernourished mice infected (UI) submitted to low and long-lasting infections by Schistosoma mansoni are unable to develop the hepatic periportal fibrosis that is equivalent to Symmers' fibrosis in humans. In this report, the effects of the host's nutritional status on parasite (worm load, egg viability and maturation) and host (growth curves, biology, collagen synthesis and characteristics of the immunological response) were studied and these are considered as interdependent factors influencing the amount and distribution of fibrous tissue in hepatic periovular granulomas and portal spaces. The nutritional status of the host influenced the low body weight and low parasite burden detected in UI mice as well as the number, viability and maturation of released eggs. The reduced oviposition and increased number of degenerated or dead eggs were associated with low protein synthesis detected in deficient hosts, which likely induced the observed decrease in transformation growth factor (TGF)- $\beta 1$ and liver collagen. Despite the reduced number of mature eggs in UI mice, the activation of TGF- $\beta 1$ and hepatic stellate cells occurred regardless of the unviability of most miracidia, due to stimulation by fibrogenic proteins and eggshell glycoproteins. However, changes in the repair mechanisms influenced by the nutritional status in deficient animals may account for the decreased liver collagen detected in the present study.
\end{abstract}

Key words: Schistosomiasis mansoni - undernutrition - liver fibrosis - cytokines

Mice that were experimentally infected by Schistosoma mansoni can develop two distinct and sometimes mixed histopathological patterns during the chronic stage of schistosomiasis: scattered small periovular granulomas with mild nonspecific reactive hepatitis and/or a concentration of circumoval granulomas causing fibrotic expansion and the development of thin fibrous tracts connecting portal spaces (murine periportal fibrosis). This fibrosis mimics the human disease known as Symmers' fibrosis or "clay pipestem" fibrosis (Andrade \& Warren 1964, Warren 1966, Andrade \& Cheever 1993).

Henderson (1993), working with inbred male CBA/J mice chronically infected with $S$. mansoni, reported the development of two syndromes that pathologically and immunologically imitate the intestinal and hepatosplenic clinical forms of the human disease. Later, Silva (2004) found that these two histological patterns (scattered granulomas and periportal fibrosis) had similar immunological profiles in well-fed BALB/c mice.

doi: $10.1590 / 0074-0276140266$

Financial support: CPqAM/FIOCRUZ, CAPES

+ Corresponding author: sheilla@cpqam.fiocruz.br

Received 16 May 2013

Accepted 17 December 2013
The periportal fibrosis is due to massive egg laying by $S$. mansoni females and the development of periovular granulomas around intrahepatic portal veins, leading to the obstruction and destruction of the vessel walls (Andrade 1987). Due to fibrogenic stimuli from antigens derived from miracidia bodies (Hang et al. 1974) and, to a lesser extent, from the eggshells themselves (de Walick et al. 2012), inflammatory cells and macrophages are activated and secrete fibrogenic cytokines such as transformation growth factor (TGF)- $\beta 1$, interleukin (IL)-13 and other mediators, which contribute to the regulation of the inflammatory response as well as stimulate the activation of hepatic stellate cells (HSCs) also known as pericytes, fat-storing cells or Ito's cells (Geerts 2001, Gressner et al. 2002).

The HSCs are located in the perisinusoidal space (Friedman 2008). They are actin-containing cells with high plasticity and the capacity to become transformed into myofibroblasts, an important matrix synthesising cell also involved in vascular remodelling of the fibrous tissue (Baptista \& Andrade 2005). In response to chronic hepatic injury, HSCs differentiate into myofibroblasts, expressing intermediary filaments of alpha-smooth muscle actin $(\alpha$-SMA) and collagen and secrete components of the extracellular matrix (Friedman 2008), whose stability is regulated by metalloproteinases and their tissue inhibitors, according to Hemmann et al. (2007). 
Investigations of the interrelationships between schistosomiasis and host nutritional status have demonstrated that mice infected by S. mansoni and fed a low-protein diet develop, in the acute stage of the disease, small periovular granulomas with fewer inflammatory cells, reduced amounts of fibrous tissue in the liver and an inability to develop the murine "pipestem"-like fibrosis or periportal fibrosis (Coutinho et al. 1997, 2003, 2007) as was seen in $30-50 \%$ of well-fed animals submitted to low and long-lasting infections (Warren 1966, Andrade \& Cheever 1993). Experiments on shifting from a deficient to a balanced diet and vice-versa, repeated infections or the use of different strains of inbred mice have been all unsuccessful (Coutinho 2004).

Previous studies on the development of the hepatic periportal fibrosis in well-nourished mice infected (WI) have demonstrated the importance of immunological mechanisms, emphasising the role of the T-helper (Th)2 response (Pearce \& MacDonald 2002) and of IL-4, IL10 and IL-13 as key cytokines for fibrogenesis (Hilkens et al. 1997). Undernourished-infected mice (UI) produce low levels of IL-4 (Oliveira et al. 2004) and IL-13 (Coutinho et al. 2010).

The host's nutritional status interferes with the course of S. mansoni infection in undernourished mice (UI), with negative effects on the growth and development of the parasites (Neves et al. 2001, 2002, Oliveira et al. 2004) and on egg release.

In this paper, the effects of the nutritional status on the biology of UI mice (growth curves) and parasites (worm load, egg viability and maturation), as well as on the collagen synthesis and the characteristics of the immunopathological response, were studied.

All these variables (nutritional status, egg unviability, low fibrogenic cytokine response, low collagen synthesis) are likely interdependent factors that influence the amount and distribution of fibrous (collagen) tissue in the liver periovular granulomas and portal spaces, explaining the absence of development of the murine type of periportal schistosomal fibrosis in UI mice.

\section{MATERIALS AND METHODS}

Animals and experimental infection - Sixty C57BL/6 mice and 100 Swiss Webster mice [for soluble egg antigen (SEA) preparation] at 21 days of age, weighing 11-15 g, were kept in individual wire-bottomed cages. They were raised and maintained at the animal facilities of Aggeu Magalhães Research Centre [Oswaldo Cruz Foundation (Fiocruz), Recife, state of Pernambuco, Brazil]. Water and food were provided ad libitum. Mice were maintained in a temperature $\left(23^{\circ} \mathrm{C}\right)$ and light-controlled environment.

Ethics statement - Animal experiments were performed in accordance with the Animal Care and Use Committee of Fiocruz (state of Rio de Janeiro), under license L 0028/07.

Experimental design and infection - Mice were infected percutaneously with 40 recently shed $S$. mansoni cercariae obtained from laboratory-raised Biomphalaria glabrata snails (Belo Horizonte strain). The animals were distributed into the following groups: group 1 [undernourished non-infected (UNI)], group 2 [undernourished-infected (UI)], group 3 [well-nourished non-infected (WNI)] and group 4 [well-nourished infected (WI)]. Infection was confirmed in each mouse by the detection of $S$. mansoni eggs in the faeces 50 days after cercarial exposure. Animals were fed their respective diet from 30 days before infection to the end of the experiment and were euthanised 60 and 150 days after infection.

Diets - Undernutrition was induced in mice by feeding them with a multi-deficient and essentially low-protein diet (7-8\% protein), planned to simulate a diet usually ingested by low-income individuals living in endemic areas of Manson's schistosomiasis in Northeast Brazil (Coutinho et al. 1997) and is thus referred to as the regional basic diet. The control diet (NUVILAB) was a pelleted commercial balanced chow for mice produced by Nuvital Nutrientes Ltda (Colombo, PR, Brazil), with $22 \%$ protein content.

Evaluation of nutritional status - Body weight was weekly recorded and food consumption was measured every day. As this experimental model of mouse undernutrition has been extensively studied in previous investigations (Coutinho 1980, Teodósio et al. 1990, Coutinho et al. 1992, 1997, 2003), it was considered unnecessary to evaluate other parameters.

Parasitological studies - Parasites recovery and counting mice were killed by intraperitoneal injection of ketamine $115 \mathrm{mg} / \mathrm{kg}$ and xylazine $10 \mathrm{mg} / \mathrm{kg}$. They were perfused after 60 (acute) and 150 (chronic) days of infection, according to the Duvall and DeWitt technique (1967). Worms recovered after perfusion of the portal system were counted and separated according to sex. Eggs in the liver and intestine were quantified after digestion with 4\% potassium hydroxide (Cheever 1970).

Oogram procedures - Fragments of the small intestine (terminal ileum), of $1 \mathrm{~cm}$ length, were removed from all animals. They were later transferred to Petri dishes containing isotonic saline, opened lengthwise with scissors to remove excess mucus, partially dried on absorbent paper, weighed and placed between a glass slide and a plastic cover. The preparation was pressed on a rubber surface padded with absorbent paper (Pellegrino et al. 1963, Pellegrino \& Faria 1965). The terminal ileum was used because this segment is the most frequent intestinal site for oviposition of several strains of $S$. mansoni in mice (Valadares et al. 1981). Using a light microscope at a magnification $100 \mathrm{X}$ or $400 \mathrm{X}$ in questionable cases, all eggs on each slide were counted and classified according to their developmental or maturation stage, following specific features of each stage. A qualitative and quantitative oogram evaluation was performed and in each fragment an average of 100 eggs were counted and classified as viable (mature, immature in 4 different development stages) or dead (calcified, with retracted miracidium, semi-transparent) according to the following features: mature eggs (containing an already developed miracidium); immature first stage (embryo at one-third of the diameter of the egg); immature second stage (embryo at one-half of the length of the egg); immature third 
stage (embryo at two-thirds of the length of the egg); immature fourth stage (embryo almost entirely occupying the eggshell) (Pellegrino et al. 1963).

Morphological studies - The livers were removed, rinsed with phosphate buffered saline, weighed and divided into several portions. One section of the liver was fixed in $10 \%$ formaldehyde for histologic examination. Tissues were embedded in paraffin and the $5 \mu \mathrm{m}$-thick sections obtained were stained with haematoxylin-eosin and picrosirius-red method for collagen (Junqueira et al. 1979). Another portion of the liver was placed in 4\% potassium hydroxide for egg counting (Cheever 1970). A liver portion weighing $100-200 \mathrm{mg}$ was used for hydroxyproline determination, according to Bergman and Loxley (1963).

Morphometry - Randomly sampled $5 \mu \mathrm{m}$-thick liver histological sections, stained with picrosirius-red for collagen, were examined by semiautomatic morphometry using the LEICA Q500 MC Image Processing and Analysis System (Leica Cambridge, Cambridge, England). For morphometric measurements, a total sectional area of $6.6 \mathrm{~mm}^{2}$ per animal was evaluated. All periovular granulomas were included. A spherical shape and normal size distribution were assumed. The following granuloma parameters were calculated: size, volume density and numerical density. The granuloma volume density was calculated as the quotient of the total granuloma profile area to the total sectional area studied per animal. The number of granulomas per unit volume of liver was assessed by applying Weibel's formula. The sectional area of red-stained fibrous tissue was directly measured and calculated as a percentage of the total area examined, as previously described (Coutinho et al. 1997, Barbosa-Júnior 2001).

Biochemical study - From each animal, a fresh liver sample was used for the determination of collagen, measured as hydroxyproline by the Bergman and Loxley (1963) spectrophotometric method B. Values for hepatic collagen were expressed in micromoles of hydroxyproline per gram of liver and corrected for intensity of infection by dividing the hydroxyproline content in the whole liver by the number of eggs per liver, results being expressed for 10,000 eggs. Calculations for this correction were made using a simplified electronic spreadsheet developed by Cheever (1987) and used in subsequent papers.

Immunofluorescence - Formalin-fixed paraffin-embedded $5 \mu \mathrm{m}$-thick sections were used for detection of $\alpha$-SMA and type-I collagen by indirect immunofluorescence. Sections were deparaffinised and heat-induced antigen retrieval in citrate buffer $(\mathrm{pH}$ 6.0) was performed. $\alpha$-SMA filaments were labelled using a biotinylated anti- $\alpha$-SMA antibody, 1:100, overnight (Novotec, Lyon, France), followed by Streptavidin Alexa-Fluor 647, 1:200, for $1 \mathrm{~h}$ (Molecular Probes, Carlsbad, CA). For type-I collagen labelling, sections were treated with rabbit polyclonal anti-type-I collagen, 1:100, overnight (Santa Cruz, Biotechnology), followed by anti-rabbit IgG conjugated with Alexa-Fluor 488, 1:200, for $1 \mathrm{~h}$ (Molecular Probes). For the detection of $\alpha$-SMA, sec- tions were mounted in VECTASHIELD ${ }^{\circledR}$ HardSet $^{\mathrm{TM}}$ Mounting Medium with DAPI H-1500 (4, 6-diamidino2-phenylindole, Vector Laboratories): cell nuclei stained blue and cytoplasms, red. For type-I collagen, sections were stained with TO-PRO ${ }^{\circledR}-3$ (carbocyanine monomer nucleic acid): nuclei stained red and type-I collagen, green. Ten random fields per mouse were studied with a Fluoview 1000 confocal microscope using a 40X objective (Olympus, Tokyo, Japan). Morphometric analysis was performed with Image ProPlus v.7.0 software (Media Cybernetics, Inc, Rockville, MD, USA).

Cell culture - After 60 and 150 days of infection, mice from all experimental groups were killed and their spleens removed under sterile conditions. For each group of mice, splenocytes were extracted from a pool of three spleens. The splenocytes were resuspended in RPMI-1640 medium (Cultilab, São Paulo, Brazil), to which $10 \mathrm{~mL}$ of $1 \%$ penicillin and streptomycin solution, 1\% L-glutamine and 10\% foetal bovine serum (Gilson) were added. Cell viability was observed after staining with 10\% Trypan Blue. Splenocytes were cultured in 24-well plates at a final concentration of $5 \mathrm{x}$ $10^{6}$ cells $/ \mathrm{mL}$ in a $5 \% \mathrm{CO}$ oven (Forma Scientific, Inc) and later stimulated with $20 \mu \mathrm{g} / \mathrm{mL}$ of SEA (Gazzinelli et al. 1983) or $5 \mu \mathrm{g} / \mathrm{mL}$ of concanavalin A. The levels of supernatant TGF- $\beta 1$ were determined after cultures of $24 \mathrm{~h}, 48 \mathrm{~h}, 72 \mathrm{~h}$ and $120 \mathrm{~h}$, in both acute and chronic phases of schistosomal infection.

TGF- $\beta 1$ cytokine detection - The levels of TGF- $\beta 1$ were determined as $n g / \mathrm{mL}$, through ELISA, using the ELISA Ready-Set-Go Development System kit (e-Bioscience, San Diego, CA, USA) and according to the manufacturer's instructions. Each result is representative of three experiments in duplicate. The kinetics of this cytokine $(24 \mathrm{~h}, 48 \mathrm{~h}, 72 \mathrm{~h}$ and $120 \mathrm{~h})$ showed that the peak of secretion was detected in the supernatant of $24 \mathrm{~h}$ cultures, the peak of secretion observed in the WI group used as a reference. Readings were performed in the Bio-Rad Laboratories model 3550 microplate reader at a wavelength of $450 \mathrm{~nm}$. The levels of TGF- $\beta 1$ in the samples were calculated utilising the Microplate Manager software v.4.0, using standard curves of their respective recombinants. The results are shown as arithmetic mean and standard error of the mean.

Statistical analysis - The data are presented as the means \pm standard error of the means. The statistical analyses performed using BioEstat software, v.5.0 (Belém, Pará, Brazil, 2007), included the Student's $t$ test or the non-parametric Mann-Whitney $U$ test, when appropriate. For all experiments, $p$-values $<0.05$ were considered statistically significant.

\section{RESULTS}

Host nutritional status is related to low body weight and low parasite burden - UI mice had lower body weight curves than WI animals, in both acute and chronic phases of schistosomal infection. However, schistosomiasis did not significantly affect the growth and development of the mice (data not shown). 
These mice showed a low worm recovery during the course of the experiment (Fig. 1A, B) with significant differences than the well-fed group (acute phase: $\mathrm{p}=$ 0.0275; chronic phase: $\mathrm{p}=0.0090)$.

Host undernutrition interferes on the amount of egg release, egg viability and evolution or maturation - Egg counts in the liver and intestine were also lower in UI animals, at both the acute and chronic phases (Fig. 1C-F). A greater number of dead eggs or remnants of eggshells were found in fragments of intestine from UI mice during both phases of the disease, with significant differences between the UI and the WI groups at the chronic phase $(p=0.0472)$. During the acute phase, the oogram of UI mice showed a significant reduction in the number of immature eggs in the first $(p=0.0018)$, third $(p=0.0009)$ and fourth $(p=0.0007)$ stages of maturation. During the chronic stage, the percentage of mature viable eggs of $S$. mansoni was significantly lower in UI animals $(\mathrm{p}=0.009)$ when compared to WI controls and a marked increase in the number of dead eggs was detected in these deficient mice.

UI C57BL/6 mice develop an immunopathology characterised by small hepatic periovular granulomas, show the reduced ability to produce hepatic collagen and do not develop periportal fibrosis.

Histopathology - In the acute phase of infection, the livers of WI mice showed many exudative periovular granulomas within medium-sized and large portal spaces
A
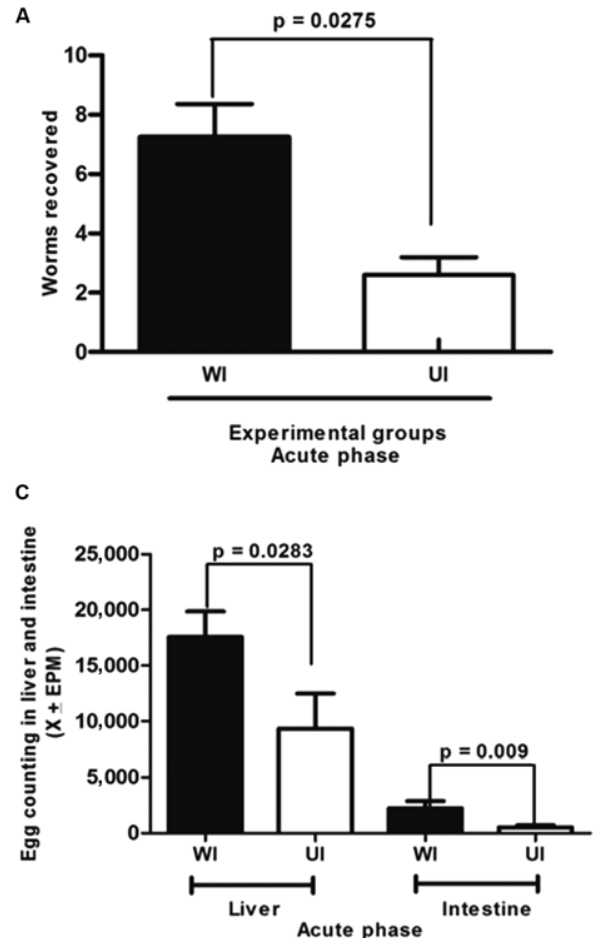

E

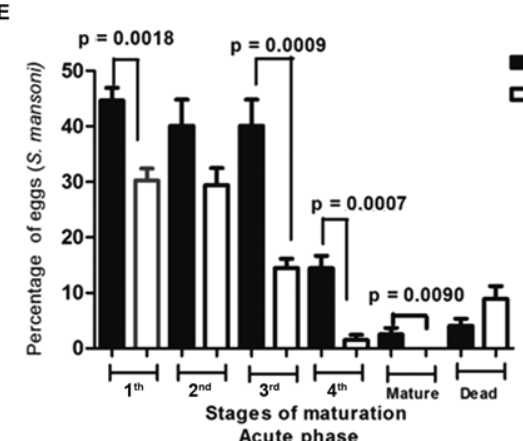

B

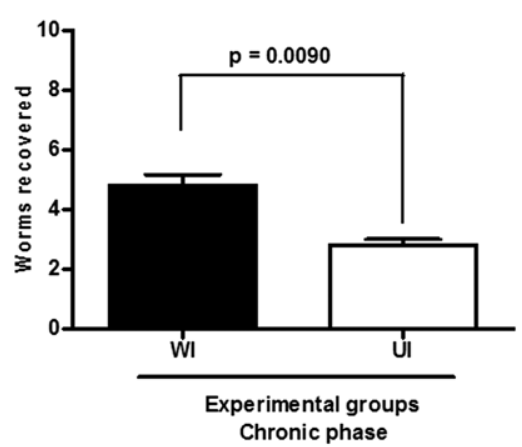

D
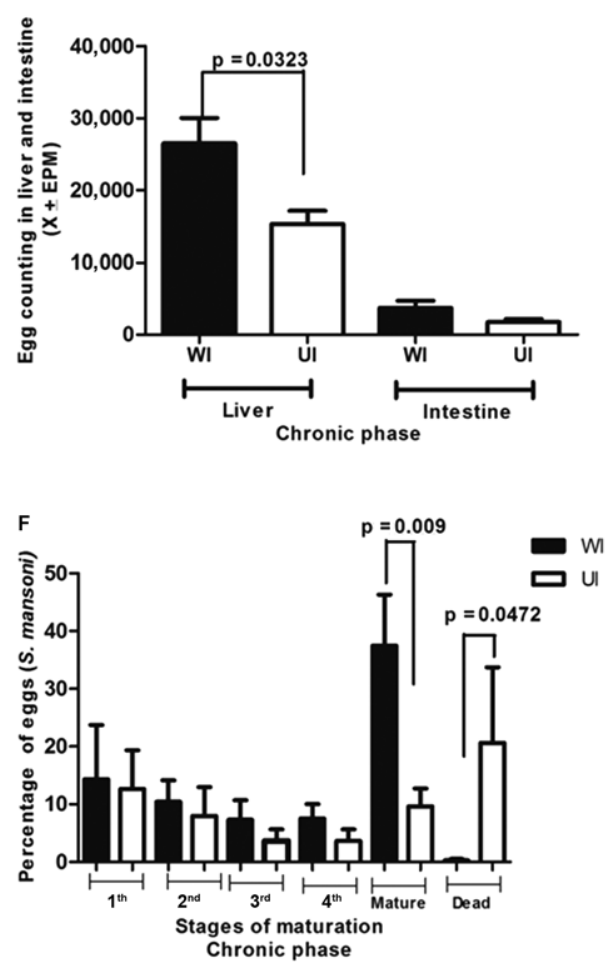

Fig. 1: worms recovered in well-nourished (WI) and undernourished-infected mice (UI) in both acute (A) and chronic (B) phases of Schistosoma mansoni infection. Egg counting in the liver and intestine of WI and UI with S. mansoni in the acute (C) and chronic (D) phases of the infection. Percentage of S. mansoni eggs in different stages of maturation in the intestinal wall of WI and UI in the acute (E) and chronic (F) phases of schistosomiasis. EPM: eggs per minute. 
or scattered in the hepatic parenchyma. They appeared isolated or in aggregates (Fig. 2A) and predominantly composed of polymorphonuclear cells, sometimes intensely infiltrated by eosinophils. A loose connective neoformation could be observed around $S$. mansoni eggs, housing inflammatory cells of the acute phase in addition to low numbers of lymphocytes and eventually macrophages. A few foci of acute coagulative necrosis were detected. UI mice showed isolated small-sized granulomas in the proximity of dead eggs or the remains of eggshells throughout the liver parenchyma (Fig. 2B).The fibrous tissue was less conspicuous and almost always absent and low numbers of scattered acute inflammatory cells were observed around some immature or dead eggs.

During the chronic phase, the livers of WI mice displayed isolated granulomas or aggregates of these structures around mature eggs and an annular or lamellar fibrous tissue with low numbers of cells (lymphocytes, plasmocytes and epithelioid cells). Only two animals out of a group of five showed a portal concentration of circumoval granulomas causing fibrotic expansion and neovascularisation of medium-sized to large portal spaces (Fig. 2C), in addition to thin fibrous tracts connecting portal spaces (murine "pipestem"-like fibrosis).

UI mice, however, showed only very small granulomas with low numbers of inflammatory cells and reduced collagen synthesis (Fig. 2D). None were able to develop the "pipestem"-like fibrosis as described in the group of WI mice.

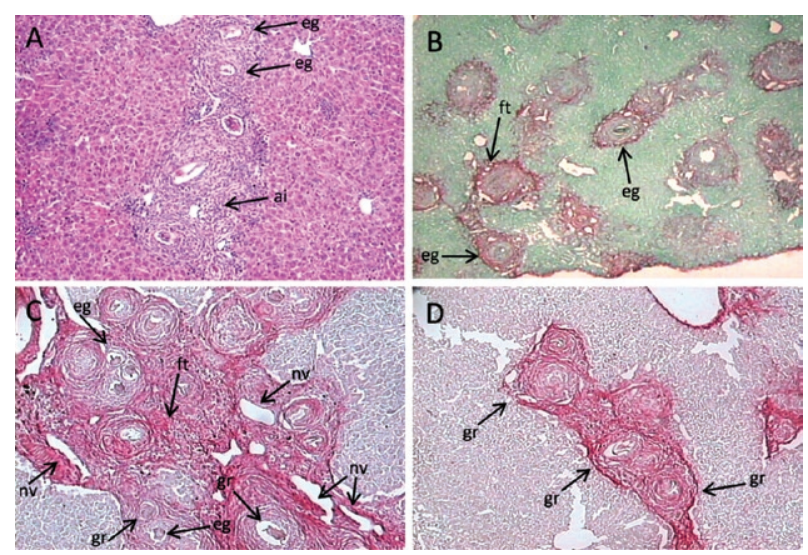

Fig. 2: liver histopathology. A: well-nourished infected mouse with Schistosoma mansoni. Conglomerates of well-developed periovular granulomas around mature eggs, acute inflammatory cellular infiltration and scarce collagen deposition (60 days of infection) (haematoxylin-eosin 50X); B: undernourished-infected mouse with S. mansoni. Small scattered periovular granulomas with a poor infiltrate of polymorphonuclear cells around remnants of eggs (60 days of infection x 100, Picrosirius-red); C: well-nourished mouse. Periportal liver fibrosis ("pipestem"-like fibrosis) showing concentration of periovular granulomas, fibrous enlargement, increased vascularisation and chronic inflammatory infiltration of the portal space (150 days of infection, x 100, Picrosirius-red); D: undernourished mice. Groups of small periovular granulomas around empty eggshells, but absence of "pipestem"-like fibrosis (150 days of infection, x 100, Picrosiriusred); ai: acute inflammatory infiltrate; eg: eggshells (remnants); ft: fibrous tissue; gr: circumoval granulomas; nv: neovascularisation.
Morphometric analysis (picrosirius-red staining) revealed that during the acute phase, the percentage of fibrous tissue in the liver of UI mice was similar to that observed in WI animals (Fig. 3A). At the chronic phase, however, the synthesis of collagen in the UI mice was less than in the WI group $(\mathrm{p}=0.0204)$ (Fig. 3B).

The liver collagen measured biochemically as hydroxyproline also showed significant differences between UI and WI mice at both the acute $(p=0.0163)$ and chronic $(p=0.009)$ phases of the infection (Fig. 3C, D). Infected mice had higher levels of hydroxyproline when compared with control non-infected groups, regardless of their nutritional status.

Morphometric analysis also revealed that the mean volume of the periovular granulomas was significantly lower in the UI group, in both acute $(p=0.009)$ and chronic $(p=0.0283)$ phases of the schistosomal infection (Fig. 4A).

Differences were not detected between UI and WI mice with regard to periovular granuloma volume density or numerical density at either phase of schistosome infection (Fig. 4B, C).

Host undernutrition had no influence on the activation of HSC, but interfered with the production of TGF $\beta-1$ and hepatic type-I collagen - During the chronic phase, HSCs were activated to similar levels, in both UI and WI mice, as demonstrated by the presence of Alexa-Fluor 647-labelled cells (Fig. 5A-E). $\alpha$-SMA-positive cells (red) were detected in periovular granulomas and in blood vessel walls. Although significant differences were found between the WI and WNI groups $(p=0.0001)$ and between the UI and UNI groups $(p=0.0001)$, no differences were detected between the WI and UI groups, at either phase of infection ( $p=0.286$ and $p=0.1029$, respectively).

Striking differences in type-I collagen were detected between UI and WI mice $(p=0.0001)$ at the chronic phase (Fig. 6A-E) with the increased deposition of collagen in periovular granulomas, vessel walls and portal spaces observed in the infected WI animals. In UI mice, the green fluorescence of collagen fibres was less evident and was restricted to a few granulomas, with portal spaces showing no evidence of increased fibrous deposition.

The mean levels of TGF- $\beta 1$ were significantly lower in the UI mice at the acute phase of infection $(p=0.0039)$, which decreased drastically as the disease progressed to the chronic phase, when titres were detected at approximately five times lower $(p=0.0039)$ than those of the WI mice (Fig. 7A, B).

\section{DISCUSSION}

Previous investigations on the interactions between the host nutritional status and infection by S. mansoni have called attention to the role of undernutrition on the biology and differentiation of the parasites, inducing phenotypic changes in adult worms of both genders (Ferreira \& Coutinho 1999, Neves et al. 2002, Oliveira et al. 2003), most likely owing to the lack of essential nutrients for their adequate growth and development. Nutritional deficiency also influences the immune response 
A
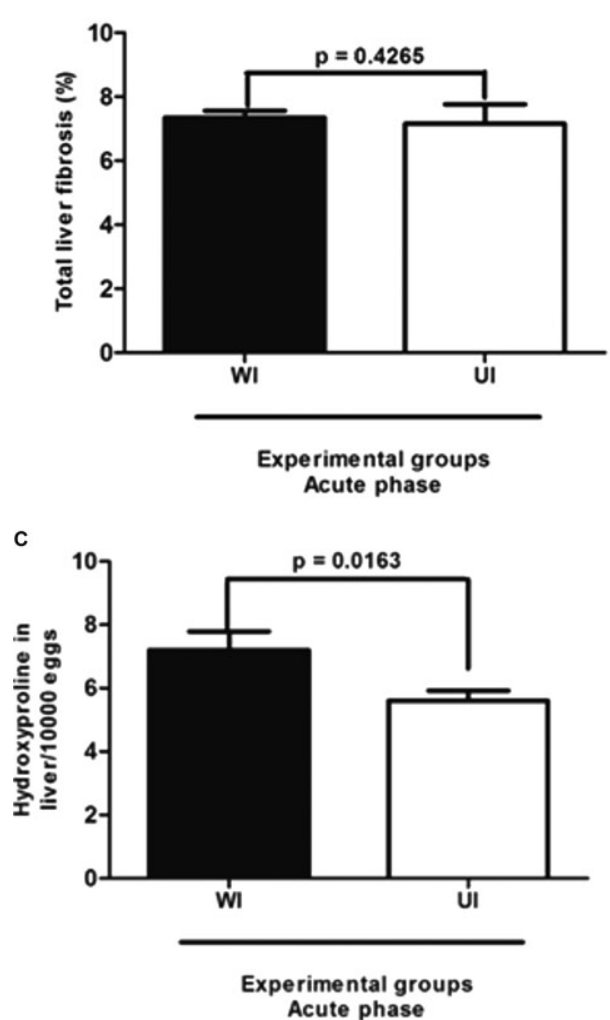

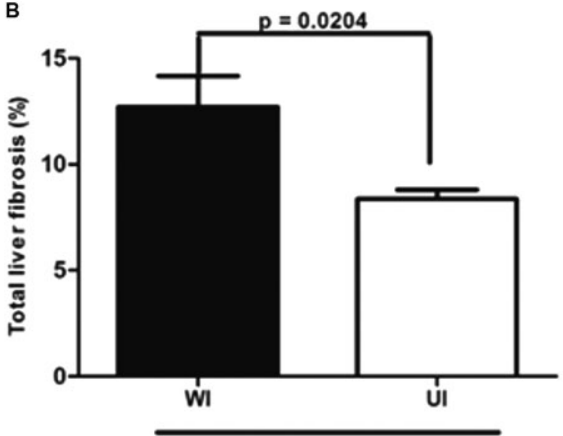

Experimental groups Chronic phase

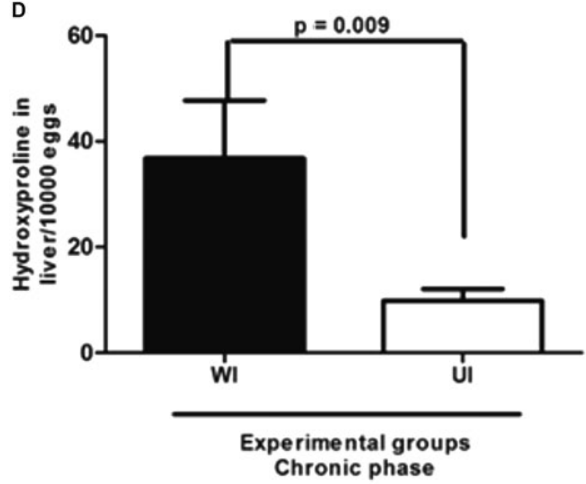

Fig. 3: morphmetric (A, B) and biochemical (C, D) measurements of liver fibrous tissue in the acute and chronic phases of Schistosoma mansoni infection in undernourished-infected (UI) and well-nourished (WI) C57BL/6 mice.
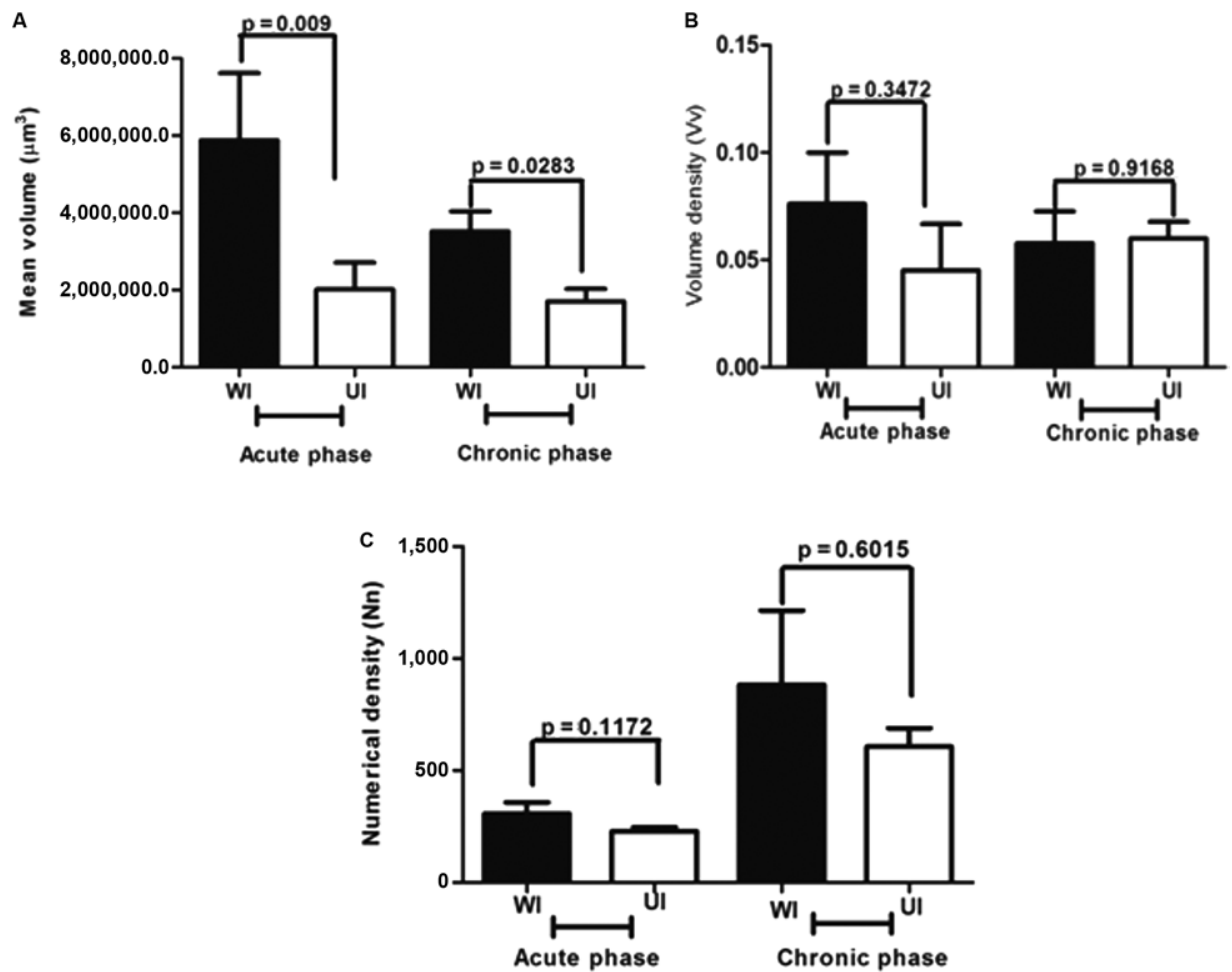

Fig. 4: morphometric measurements of the mean volume (A), volume density (B) and numerical density (C) of egg granulomas in undernourished-infected (UI) and well-nourished (WI) mice in the acute and chronic phases of Schistosoma mansoni infection. 
and immunopathology of schistosomiasis in the murine experimental host (Coutinho 2004, Oliveira et al. 2004, Coutinho et al. 2007, 2010).

Schistosomal hepatic fibrosis (Symmers' fibrosis) is a chronic lesion involving essentially portal spaces, whose etiopathogenesis is still incompletely understood. In humans, both periovular granulomas and a diffuse progressive periportal fibrosis contributing to the increased amount of fibrous tissue develop within the liver.

The experimental "pipestem"-like liver fibrosis (Symmers' fibrosis of humans) that develops in 30-50\% of mice infected by S. mansoni (Andrade 1987, Andrade \& Cheever 1993) cannot be reproduced in UI outbred and/or inbred mouse models (Coutinho 2008). Different experimental approaches that have tried to reproduce the lesion in UI mice have been unsuccessful thus far (Coutinho 2004). However, further studies on the immunological profile of these animals provided promising results regarding the role of some cytokines secreted at both the acute (60 days) and chronic stages (150 days) of murine schistosomiasis (Coutinho et al. 2010).

It has been previously reported that schistosomeundernourished infected mice are able to develop a humoral immune response, but antibody titres are much lower than in control well-fed animals (Oliveira et al. 2004, Coutinho et al. 2010). The production of the cytokines interferon (IFN)- $\gamma$, IL-4 and IL-10 is lower in the UI mice, but in INOS-knockout mice, as infection progresses to the chronic phase, the kinetics of IFN- $\gamma$ runs an antagonistic course when compared to that of WI animals (Ramos et al. 2006). On the other hand, the secretion of IL-13, a pro-fibrogenic cytokine, at the chronic phase, has been found to be at alternatively low and high levels of concentrations in splenocyte culture supernatants (Coutinho et al. 2010). The Th2 cytokines and, in particular, IL-13 and the IL-13 receptor (IL-13R $\alpha 2$ ) appear to be crucial for the hepatic fibrogenesis associated with schistosomal infection (Wynn et al. 2004).
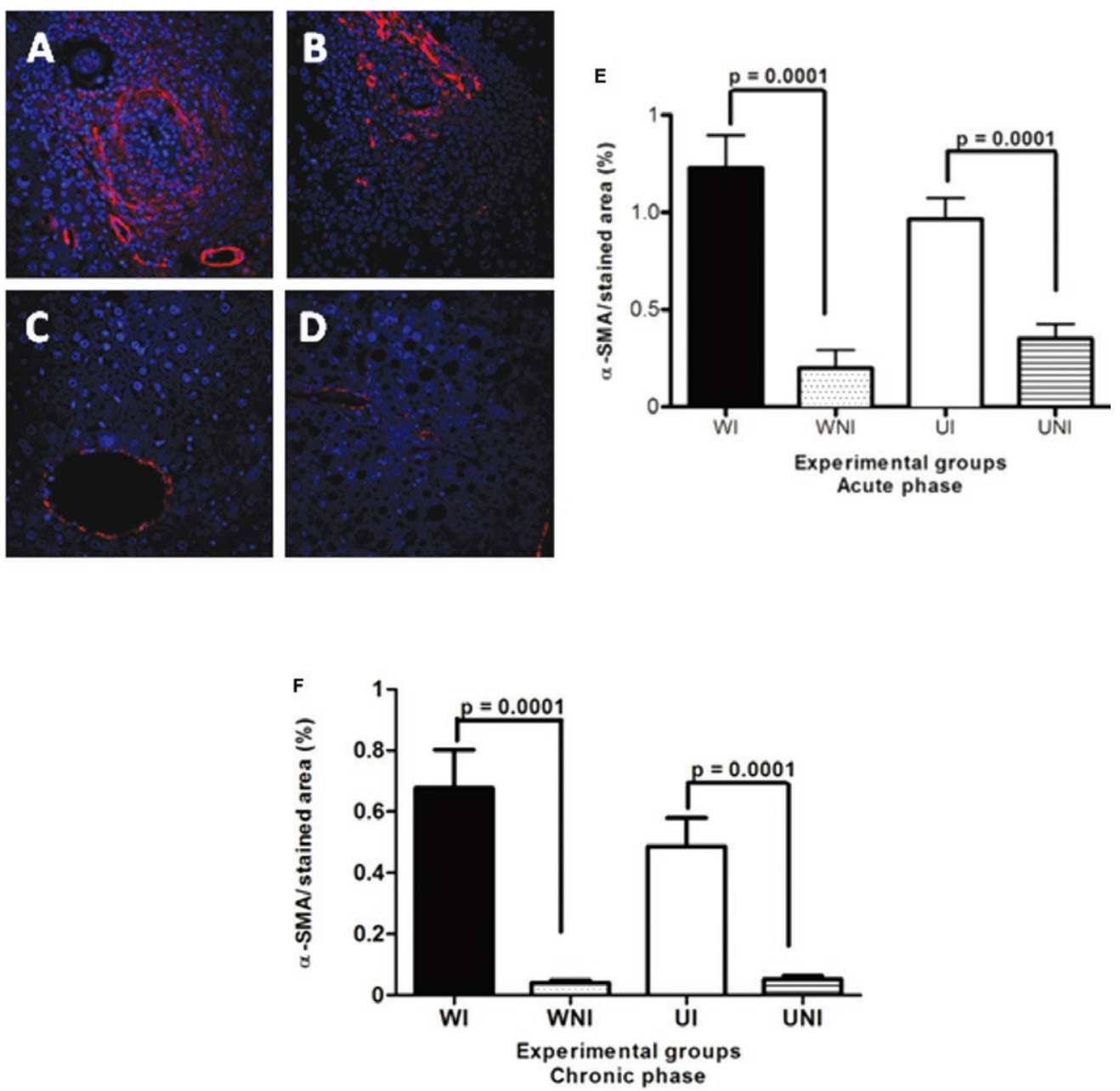

Fig. 5: immunolabelling by Alexa-Fluor 647 for alpha-smooth muscle actin ( $\alpha$-SMA) on myofibroblasts (red) and vascular walls in the liver of mice chronically infected by Schistosoma mansoni using the indirect fluorescence technique. Hepatic cells nuclei were stained with DAPI (blue). Data represent the mean and standard error of 10 sections per mouse in groups of five animals. Differences regarding the amount of hepatic stellate cells between UI and WI mice were not statistically significant in both phases. A: well-nourished infected (WI); B: undernourished-infected (UI); C: well-nourished non-infected (WNI); D: undernourished non-infected (UNI) (400X). 
In this study, the host nutritional status was related to low body weight curves, low parasite burdens and low egg loads detected in UI mice. It was found that host protein undernutrition negatively interfered with tissue
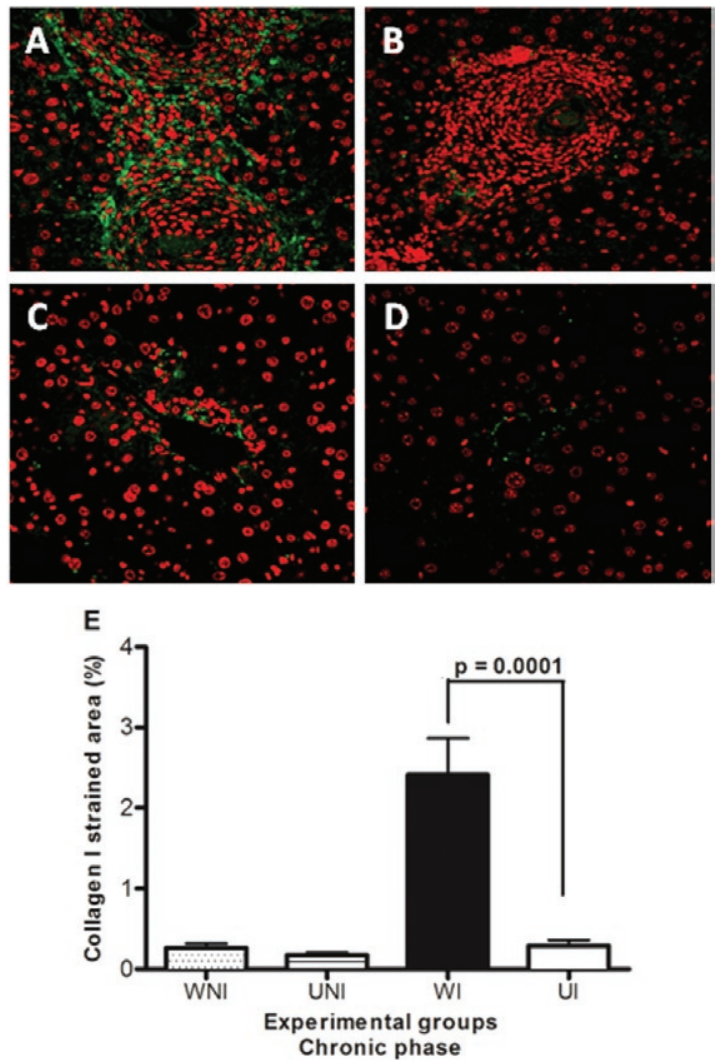

Fig. 6: immunolabelling by Alexa-Fluor 488 for collagen I (green) in the liver of mice chronically infected by Schistosoma mansoni using the indirect fluorescence technique. Hepatic cells nuclei were stained with TO-PRO 3 (red). Data represent the mean and standard error of 10 sections per mouse in groups of five animals. Significant results were detected between UI and WI mice $(p=0.0001)$. A: well-nourished infected (WI); B: undernourished-infected (UI); C: well-nourished non-infected (WNI); D: undernourished non-infected (UNI) (400X). egg release, as well as on egg viability and the degree of maturation (oogram), as a high metabolism appears to be necessary for a perfect oogenesis by $S$. mansoni adult females (Tempone et al. 2002).

UI C57BL/6 mice infected with $S$. mansoni developed a $\mathrm{CD}^{+}$T-cell mediated immunopathology characterised by small hepatic granulomas surrounding parasite eggs. This pathological finding is in line with previous reports (Cheever 1987, Rutitzky et al. 2009). The high expression of type-I collagen was detected in the periovular granulomas of WI mice at the early and/or final collagenous stages (productive granulomas), as well as on blood vessel walls. In UI animals, however, type-I collagen deposition was less evident and restricted to a few granulomas with statistically significant differences between the UI and WI groups. In the chronic stage of schistosomiasis, the amount of collagen (hydroxyproline) was approximately four times less in the UI group when compared to well-fed animals.

The data gathered thus far suggest that nutritional deficiency interferes directly with connective tissue changes occurring in murine hepatic schistosomiasis (Coutinho et al. 2003).

Recently, HSCs have gained increasing attention, not only as contractile cells, but also as obligatory regulators of vascular development (Lee et al. 2007), stabilisation, maturation and remodelling of the connective matrix. This is strongly indicative of the role played by these capillary-associated actin-containing cells in the remodelling of the extracellular matrix and associated vascular lesions (Andrade 2009). The consistent morphological association between HSCs and extracellular matrix reinforces their important role in hepatic fibrogenesis. $\alpha$-SMA, a cytoskeletal protein, is one of the six actin isoforms expressed in mammalian tissue and is the single most reliable marker of stellate cells activation and differentiation into myofibroblasts (Friedman 2008). UI and WI mice were able to activate HSCs to similar levels, as shown by Alexa-Fluor 647 positively labelled cells expressing $\alpha$-SMA in their cytoplasms. These positive cells (red) could be observed in periovular granulomas and blood vessel walls at both the acute and chronic phases of schistosomal infection. Despite this, the production
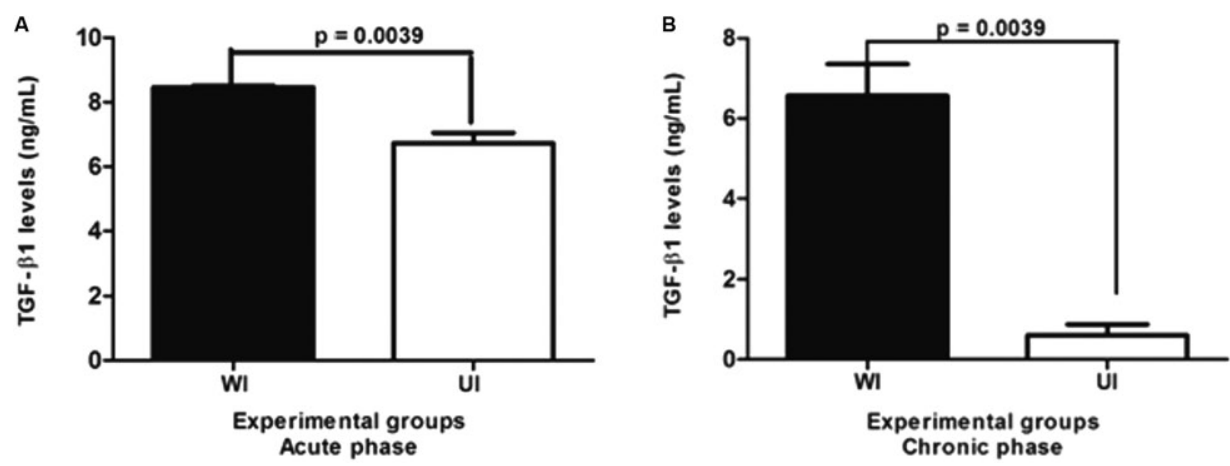

Fig. 7: levels of transformation growth factor (TGF)- $\beta 1$ in the supernatant of splenic cells (24 h culture) in undernourished-infected (UI) and well-nourished infected (WI) mice with Schistosoma mansoni in the acute (A) and chronic (B) phases of the infection. 
of type-I collagen in the chronic phase was significantly lower in UI mice, but this difference appeared to be related to the interference by dietary protein deficiency on the synthesis of collagen and likely other elements of the extracellular matrix (Coutinho et al. 2003).

Studies on the cellular kinetics of hepatic fibrosis have demonstrated the involvement of different cell types, in addition to HSCs, including eosinophils and macrophages and their relationships to the development of the granulomatous response and the production of profibrotic cytokines. The deposition of eggs by S. mansoni followed by the release of SEA incites a granulomatous response in which $\mathrm{CD}^{+} \mathrm{T}$ cells (Mathew \& Boros 1986) and eosinophils (Rumbley et al. 1999) play an important role. Additionally, $\mathrm{CD}^{+} \mathrm{T}$ cells, B cells and M2 macrophages (alternatively activated macrophages) play a role in the formation and regulation of hepatic granulomas (Herbert et al. 2004, Hams et al. 2013). It has been found that M2 macrophages induced by Th2 responses promote collagen synthesis and fibrogenesis via the metabolism of L-arginine to proline and polyamine by arginase-1 (Song et al. 2000).

In this study, the levels of TGF- $\beta 1$ in UI were significantly lower at the beginning of the infection (acute phase), falling drastically to levels approximately fivetimes lower than those detected from WI animals at the chronic phase.

The reduced egg laying in tissues and the increase in the amount of degenerated and dead eggs detected in UI mice did not entirely impair the activation of HSCs because fibrogenic stimuli from the remaining miracidia bodies and even from immunogenic cellular proteins and glycoprotein molecules derived from the eggshells (de Walick et al. 2012) were sufficient to induce the differentiation of HSCs (Ito's cells, perisinusoidal cells, pericytes) into myofibroblasts. Thus, TGF- $\beta 1$ was produced, although at lower concentrations.

The results obtained in this experiment suggest that host malnutrition is directly responsible for the reduced egg laying and low maturation of S. mansoni eggs, leading to a decreased release of immunogens and thus affecting the expression of fibrogenic cytokines such as TGF- $\beta 1$, in addition to IL-4, IL-10 and IL-13, as previously reported (Coutinho et al. 2010). The low expression of fibrogenic cytokines, however, is sufficient to activate HSCs, but these cells in UI mice are unable to adequately synthesise type-I collagen. Dietetic protein deficiency, together with the low immunogenic stimulus generated by the reduced oviposition and egg unviability, may account for the low liver collagen production and the inability of UI mice to develop the murine type of liver periportal fibrosis.

\section{ACKNOWLEDGEMENTS}

To Prof Tetsuo Tashiro, for suggestions on statistical techniques, to Roberto Werkaüser, for useful comments, and to Maria do Carmo Alves de Lima, for supply of the Brij L23 solution.

\section{REFERENCES}

Andrade ZA 1987. Pathogenesis of pipe-stem fibrosis of the liver (experimental observation on murine schistosomiasis). Mem Inst Oswaldo Cruz 82: 325-334.
Andrade ZA 2009. Schistosomiasis and liver fibrosis. Parasite Immunol 31: 656-663.

Andrade ZA, Cheever AW 1993. The characterization of the murine model of schistosomal periportal fibrosis ("pipestem" fibrosis). Int J Exp Pathol 74: 195-202.

Andrade ZA, Warren KS 1964. Mild prolonged schistosomiasis in mice: alterations in host response with time and the development of portal fibrosis. Trans R Soc Trop Med Hyg 58: 53-57.

Baptista AP, Andrade ZA 2005. Angiogenesis and schistosomal granuloma formation. Mem Inst Oswaldo Cruz 100: 183-185.

Barbosa-Júnior AA 2001. Morphological computer-assisted quantitative estimation of stained fibrous tissue in liver sections: applications in diagnosis and experimental research. $J$ Bras Patol 37: $197-200$.

Bergman I, Loxley R 1963. Two improved and simplified methods for the spectrophotometric determination of hydroxyproline. Anal Chem 35: 1961-1965.

Cheever AW 1970. Relative resistance of the eggs of human schistosomes to digestion in potassium hydroxide. Bull World Health Organ 43: 601-603.

Cheever AW 1987. Variation of hepatic fibrosis and granuloma size among mouse strains infected with Schistosoma mansoni. Am J Trop Med Hyg 37: 85-97.

Coutinho EM 1980. Estado nutricional e esquistossomose. Rev Soc Bras Med Trop 13: 91-96.

Coutinho EM 2004. Malnutrition and hepatic fibrosis in murine schistosomiasis. Mem Inst Oswaldo Cruz 99 (Suppl. I): 85-92.

Coutinho EM 2008. Schistosoma mansoni e esquistossomose: uma visão multidisciplinar In OS Carvalho, PMZ Coelho, HL Lenzi, Patologia da esquistossomose na má-nutrição: uma visão abrangente, 1st ed., Fiocruz, Rio de Janeiro, p. 655-685.

Coutinho EM, Abath FGC, Barbosa CS, Domingues ALC, Melo MCV, Montenegro SML, Lucena MAF, Romani SAM, Souza WV, Coutinho AD 1997. Factors involved in Schistosoma mansoni infection in rural areas of Northeast Brazil. Mem Inst Oswaldo Cruz 92: 707-715.

Coutinho EM, Barros AF, Barbosa Jr A, Oliveira SA, Silva LM, Araújo RE, Andrade ZA 2003. Host nutritional status as a contributory factor to the remodeling of schistosomal hepatic fibrosis. Mem Inst Oswaldo Cruz 98: 919-925.

Coutinho EM, de Oliveira SA, de Barros AF, Silva FL, Ramos RP 2010. Manson's schistosomiasis in the undernourished mouse: some recent findings. Mem Inst Oswaldo Cruz 105: 359-366.

Coutinho EM, Ferreira HS, de Freitas LPCG, Silva MR, Cavalcanti CL, Samico MJA 1992. Nutrition and acute schistosomiasis. Mem Inst Oswaldo Cruz 87 (Suppl. IV): 297-301.

Coutinho EM, Silva FL, Barros AF, Araújo RE, Oliveira SA, Luna CF, Barbosa Jr AA, Andrade ZA 2007. Repeated infections with Schistosoma mansoni and liver fibrosis in undernourished mice. Acta Trop 101: 15-24.

de Walick S, Tielens AG, van Hellemond JJ 2012. Schistosoma mansoni: the egg, biosynthesis of the shell and interaction with the host. Exp Parasitol 132: 7-13.

Duvall RH, DeWitt WB 1967. An improved perfusion technique for recovering adult schistosomes from laboratory animals. $\mathrm{Am} J$ Trop Med Hyg 16: 483-486.

Ferreira HS, Coutinho EM 1999. Should nutrition be considered as a supplementary measure in schistosomiasis control? Ann Trop Med Parasitol 93: 437-447. 
Friedman SL 2008. Hepatic stellate cells - protean, multifunctional and enigmatic cells of the liver. Physiol Rev 88: 125-172.

Gazzinelli G, Katz N, Rocha RS, Colley DG 1983. Immune response during human schistosomiasis mansoni. X. Production and standardization of an antigen-induced mitogenic activity by peripheral blood mononuclear cells from treated but not active cases of schistosomiasis. J Immunol 130: 2891-2895.

Geerts A 2001. History, heterogeneity, developmental biology and functions of quiescent hepatic stellate cells. Semin Liver Dis 21: 311-335.

Gressner AM, Weiskirchen R, Breitkopf K, Dooley S 2002. Roles of TGF-beta in hepatic fibrosis. Front Biosci 7: 793-807.

Hams E, Aviello G, Fallon PG 2013. The Schistosoma granuloma: friend or foe? Front Immunol 4: 1-8.

Hang LM, Warren KS, Boros DL 1974. Schistosoma mansoni: antigenic secretions and the etiology of egg granulomas in mice. Exp Parasitol 35: 288-298.

Hemmann S, Graf J, Roderfeld M, Roeb E 2007. Expression of MMPs and TIMPs in liver fibrosis - a systematic review with special emphasis on anti-fibrotic strategies. J Hepatol 46: 955-975.

Henderson GS 1993. Two distinct pathologic syndromes in male CBA/J inbred mice with chronic Schistosoma mansoni infections. Am J Pathol 142: 703-714.

Herbert DR, Hölscher C, Mohrs M, Arendse B, Schwegmann A, Radwanska M, Leeto M, Kirsch R, Hall P, Mossmann H, Claussen B, Förster I, Brombacher F 2004. Alternative macrophage activation is essential for survival during schistosomiasis and downmodulates Thelper 1 responses and immunopathology. Immunity 20: 623-635.

Hilkens CM, Kalinski P, de Boer M, Kapsenberg ML 1997. Human dendritic cells require exogenous interleukin-12-inducing factors to direct the development of naïve T-helper cells toward the Th1 phenotype. Blood 90: 1920-1926.

Junqueira LCU, Bignolos G, Brentani RR 1979. Picrosirius staining plus polarization microscopy, a specific method for collagen detection in tissue section. Histochem J 11: 447-455.

Lee JS, Semela D, Iredale J, Shah VH 2007. Sinusoidal remodeling and angiogenesis: a new function for the liver-specific pericyte? J Hepatol 45: 817-823.

Mathew RC, Boros DL 1986. Anti-L3T4 antibody treatment suppresses hepatic granuloma formation and abrogates antigen-induced interleukin-2 production in Schistosoma mansoni infection. Infect Immun 54: 820-826.

Neves RH, Machado-Silva JR, Pelajo-Machado M, Oliveira SA, Coutinho EM, Lenzi HL, Gomes DC 2001. Morphological aspects of Schistosoma mansoni adult worms isolated from nourished and undernourished mice: a comparative analysis by confocal laser scanning microscopy. Mem Inst Oswaldo Cruz 96: 1013-1016.

Neves RH, Oliveira SA, Machado-Silva JR, Coutinho EM, Gomes DC 2002. Phenotypic characterization of Schistosoma mansoni adult worms recovered from undernourished mice: a morphometric study focusing on the reproductive system. Rev Soc Bras Med Trop 35: 405-407.
Oliveira SA, Barbosa Jr AA, Gomes DC, Machado-Silva JR, Barros AF, Neves RH, Coutinho EM 2003. Morphometric study of Schistosoma mansoni adult worms recovered from undernourished infected mice. Mem Inst Oswaldo Cruz 98: 623-627.

Oliveira SA, Silva LM, Barbosa-Júnior AA, Ribeiro-dos-Santos R, Coutinho EM, Andrade ZA, Soares MB 2004. Decreased humoral and pathologic responses in undernourished mice infected with Schistosoma mansoni. Parasitol Res 93: 30-35.

Pearce EJ, MacDonald AS 2002. The immunobiology of schistosomiasis. Nat Rev Immunol 2: 499-511.

Pellegrino J, Faria J 1965. The oogram method for the screening of drugs in schistosomiasis mansoni. Am J Trop Med Hyg 14: 363-369.

Pellegrino J, Oliveira CA, Faria J 1963. The oogram in the study of relapse in experimental chemotherapy of schistosomiasis mansoni. J Parasitol 49: 365-370.

Ramos RP, Costa VMA, Melo CF, Souza VMO, Malagueño E, Coutinho EM, Abath FGC, Montenegro SML 2006. Preliminary results on interleukin- 4 and interleukin-10 cytokine production in malnourished, inducible nitric oxide synthase-deficient mice with schistosomiasis mansoni infection. Mem Inst Oswaldo Cruz 101 (Suppl. I): 331-332.

Rumbley CA, Sugaya H, Zekavat AS, El Rafaei M, Perrin PJ, Philips SM 1999. Activated eosinophils are the major source of Th2associated cytokines in the schistosome granuloma. J Immunol 162: 1003-1009.

Rutitzky LI, Smith PM, Stadecker JM 2009. T-bet protects against exacerbation of schistosome egg-induced immunopathology by regulating Th17-mediated inflammation. Eur J Immunol 39: 2470-2481.

Silva ML 2004. Comparasion of immune responses of Shistosoma mansoni-infected mice with distinct chronic forms of the disease. Acta Trop 91: 189-196.

Song E, Ouyang N, Horbelt M, Antus B, Wang M, Exton MS 2000. Influence of alternatively and classically activated macrophages on fibrogenic activities of human fibroblasts. Cell Immunol 204: 19-28.

Tempone AJ, Furtado DR, Gimba ERT, Oliveira FMB, Rumjanek FD 2002. Dolichol phosphate mannose synthase is differentially expressed in male and female worms of Schistosoma mansoni. Comp Biochem Physiol B Biochem Mol Biol 131: 465-474.

Teodósio NR, Lago ES, Romani SA, Guedes RC 1990. A regional basic diet from Northeast Brazil as a dietary model of experimental malnutrition. Arch Latinoam Nutr 40: 533-547.

Valadares TE, Coelho PM, Pellegrino J, Sampaio IB 1981. Schistosoma mansoni: aspects of the oviposition of the LE' strain in mice infected with a couple of worms. Rev Inst Med Trop 23: 6-11.

Warren KS 1966. The pathogenesis of "clay-pipestem cirrhosis" in mice with chronic schistosomiasis mansoni with a note on the longevity of the schistosomes. Am J Pathol 49: 477-489.

Wynn TA, Thompson RW, Cheever AW, Mentink-Kane MM 2004. Immunopathogenesis of schistosomiasis. Immunol Rev 201: 156-167. 